\title{
STRATEGIES OF TRANSLATION
}

The paper is concerned with the strategies of written translation. The first section deals with various definitions of the notion of translation strategy, terms used to describe that notion and classifications of translation strategies. The second section presents the results of some empirical studies on translation strategies. In the third section, Krzysztof Hejwowski's concept of translation strategies is laid out and the results of a pilot study based on this concept are described.

Key words: translation, translation process, translation strategy

The present paper is intended as a preliminary attempt to organize various considerations related to strategies of translation. The subject will be developed further in my PhD dissertation prepared at the University of Social Sciences and Humanities under the supervision of Barbara Bokus.

\section{Theoretical background. Definitions and basic distinctions}

As noted by Lörscher (1991, p. 70), the concept of translation strategy seldom appears in translation theory and is not precisely defined. Several authors (Chesterman, 1997; Hejwowski, 2004; Kearns, 2009) remark that not only is the term strategy used to describe different concepts but also various terms are used to express the same meaning.

According to Lörscher, translation strategy is "a potentially conscious procedure for the solution of a problem which an individual is faced with when translating a text segment from one language to another" (Lörscher, 1991, p. 76).

Address for correspondence: Dagmara Płońska, Faculty of Psychology, University of Social Sciences and Humanities, Chodakowska 19/31, 03-815 Warsaw, Poland. E-mail: dplonska@swps.edu.pl 
Hejwowski offers a broader definition as "a translator's (consciously or unconsciously) preferred procedure within an entire text or its significant passages" and distinguishes this concept from technique, which he defines as "the choice of a solution to a specific problem encountered during the translation process" (Hejwowski, 2004, p. 76). This distinction corresponds to that between "local" and "global" translation strategies made by several authors (Séguinot, 1989; Lörscher, 1991; Jääskeläinen, 1993, cited by Kearns, 2009, p. 283). In the words of Chesterman (1997, pp. 90-91), "global strategies" are applied in response to the question "how to translate this text or this kind of text", while "local strategies" correspond to the question "how to translate this structure/this idea/this item".

The classic concept of Vinay and Darbelnet (1958/2000) and that of Newmark (1988) used the terms "translation method" and "translation procedure" that might be equated with the terms "global" and "local" strategies. Vinay and Darbelnet mention only two methods of translating: direct, or literal translation and oblique translation. Within the framework of direct translation they list three procedures: borrowing, calque and literal translation. In the context of oblique translation they enumerate four procedures: transposition, modulation, equivalence and adaptation; however, the latter two terms are used in a different sense than in modern translation theory. According to the authors, transposition consists of "replacing one word class with another without changing the meaning of the message", for example replacing the phrase "dès son lever" with the expression "as soon as he gets/got up" (Vinay \& Darbelnet, $1958 / 2000$, p. 88). Modulation is "a variation of the form of the message, obtained by a change in the point of view", like in the translation of the phrase "It is not difficult to show" to the expression "Il est facile de démontrer" (Ibid., p. 89). Equivalence consists in rendering "the same situation ... by two texts using completely different stylistic and structural methods", like in the case of idioms, for example "Il pleut à seaux" and "It is raining cats and dogs" (Ibid., p. 90). Adaptation is used "in those cases where the type of situation being referred to by the SL message is unknown in the TL culture" and is especially frequent in the translation of book and film titles (Ibid., p. 91).

According to Newmark, "while translation methods relate to whole texts, translation procedures are used for sentences and the smaller units of language" (Newmark, 1988, p. 81). Newmark's classification of translation methods and procedures partially overlaps that of Vinay and Darbelnet but is much more detailed. It is also based on the opposition between literal and free translation.

Königs (1987) and Wills (1983), cited by Lörscher (1991), conceive translation methods and translation strategies differently. In their view, translation strategies are "procedures, often of a highly individual kind, which are applied when a source-language text is transferred into the target-language" and which "can, but need not, result in an optimal translation", while translation methods "are supraindividual, tried and tested procedures which, when applied systematically by the 
translator, guarantee a high degree of success (Königs, 1987, cited by Lörscher, 1991, p. 70). Nonetheless, Lörscher notes that "even though this distinction is theoretically reasonable, it must be acknowledged that translation strategies have hardly been investigated in translation theory and that practicable translation methods are not much more than a desideratum at the moment" (1991, p. 71).

Apart from the distinction between "local" and "global" ones, translation strategies can be divided into "procedural" and "textual" (Molina \& Hurtado Albir, 2002 , cited by Kearns, 2009, p. 283). Strategies in the procedural sense are investigated by Lörscher $(1991,2005)$ who takes a descriptive approach to translation strategies and among their elements lists realizing a translation problem, testing a solution to the translation problem, monitoring text segments, rephrasing text segments and organizing discourse. Kearns observes that "As mental phenomena, strategies in this sense are themselves unobservable, although they may be reconstructed by researchers through analysis of strategy indicators." (Kearns, 2009 , p. 283). Also Séguinot takes a procedural approach to translation strategies and names three global strategies used by translators: "(a) translate without interruption for as long as possible, (b) correct surface errors immediately ... but leave errors involving meaning until a natural break occurs, typically at the end of a clause or sentence, and (c) leave the monitoring for qualitative or stylistic errors in the text to the revision stage" (Séguinot, 1989, cited by Bell, 1998, p. 188).

In turn, the term "textual strategies" applies to different forms of textual manipulation. It is used to describe the results of procedures rather than the procedures themselves (Kearns, 2009, p. 283). An example of such strategies can be Chesterman's classification which distinguishes three main groups of strategies, namely syntactic, semantic and pragmatic strategies (Chesterman, 1997, p. 93). Also, the aforementioned classifications of Vinay and Darbelnet and of Newmark might be regarded as relating to textual strategies.

Finally, the strategies of translation can be divided into "comprehension strategies", referring to the analysis of the source text, and "production strategies", referring to the production of the target text (Gile, 1992, 1995, cited by Chesterman, 1997, p. 93). As noted by Kearns, although comprehension strategies were the subject of some research (e.g. Kupsch-Losereit, 2000), much greater attention was paid to production strategies. Besides the classifications cited above, detailed classifications of production strategies were proposed by, among others, Nida (1964), Catford (1965), Malone (1988) and van Leuven-Zwart (1989/1990) (Kearns, 2009, p. 283).

\section{Empirical research on translation strategies}

Empirical research on translation strategies is a part of broader processoriented translation research. The researchers adopted different approaches to translation strategies and used various definitions of the notion. Therefore, in 
this section I will concentrate on the results of the studies that are relevant to my research project in progress.

Many findings suggest that the predominant strategy of individuals with little experience in translation consists in replacing words of one language with those of another without more complex text analysis. As noted by Lörscher, "most of the foreign language students ... produce translations mainly by an exchange of language signs" (Lörscher, 2005, p. 605). Königs and Kaufmann observe that translation procedures of foreign language students are vocabulary-centered and their mental activity is focused mostly on the vocabulary to the detriment of the grammar (Königs and Kaufmann, 1996, pp. 18-19). Tirkkonen-Condit remarks that "novices tend to approach a translation task as a series of lexical or phrasal problems that are to be solved in the order in which they appear in the text. In novices' performance, translation tends to proceed word by word, phrase by phrase, sentence by sentence" (Tirkkonen-Condit, 2005, p. 408).

On the other hand, research carried out by Tirkkonen-Condit (2002, cited in Tirkkonen-Condit, 2005) shows that a tendency to translate literally occurs in both beginner and experienced translators. This is visible not only in the translation process but also in the finished translations. The author claims that literal translation is the default procedure used by a person translating a text until that person notices a problem with the text of the translation. This finding is in line with the theoretical considerations of Newmark, who believes literal translation to be the basic translation procedure (Newmark, 1988, p. 70). The tendency to translate literally as a default procedure was also noted by Nili Mandelblit. In her psycholinguistic experiment bilinguals were asked to translate idioms from French into English and vice versa, each subject translating into their mother tongue. According to the researcher's hypothesis, the idioms with a different cognitive mapping in the target language would be more difficult and thus take more time to translate. The results confirmed this hypothesis but also showed that "when translating DMC (different mapping condition) sentences, subjects tended to first suggest a word-to-word (and 'same mapping') translation for the source sentence and only later propose the better translation" (Mandelblit, 1996, p. 493, cited by Tirkkonen-Condit, 2005, p. 409).

According to Lörscher, translation processes observed in non-professional and professional translators have a lot in common. The author investigated translation strategies used by foreign language students (1991) and compared them to those used by professional translators (2005). The results of his studies suggest that translation processes observed in the two groups do not involve significant differences in terms of the kind of strategy used; the processes do differ, though, in the frequency and distribution of different strategies (Lörscher 2005, p. 604).

Contrary to the above, Jääskeläinen observes that the translation processes of professionals and non-professionals differ qualitatively. She explains the difference as follows: "while some kinds of processing gradually become automa- 
tized, other kinds of processing will take up the released processing capacity in working memory (see Jääskeläinen \& Tirkkonen-Condit, 1991, p. 105; Gerloff, 1988, p. 54). Thus, there will be more processing capacity to be used for, say, higher-level text production strategies than in the processes used by novices" (Jääskeläinen, 1996, p. 67).

As far as the differences between the translation strategies used by professionals and non-professionals are concerned, Tirkkonen-Condit notes that beginner translators and amateurs focus on lexical units and seek information in external translation aids, while experts concentrate on the text itself, its semantic, pragmatic and inter-textual aspects, trying to extract as much information as possible. The comprehension strategies of amateurs have a local orientation, while those of experts are global. The same can be said in regard to production strategies. The experts tend to make some global decisions about the emerging text of the translation (e.g. about its overall style) at a relatively early stage of the process (Tirkkonen-Condit, 2005, p. 406).

These findings are in consonance with those of Jääskeläinen (1996). The researcher discovered that the authors of mediocre and poor translations rely more on linguistic knowledge, while the authors of good translations tend to apply world knowledge. According to her, "in the good processes most of the attention is directed at text comprehension, at relating the text to the extra-textual world. The less successful processes seem to remain more exclusively at the linguistic surface level.” (Jääskeläinen, 1996, p. 69). Similarly, analyzing translation processes of foreign language students, Königs and Kaufmann note a "huge restriction of contextualization activity which occurs only on the level of the phrase, or even of the syntagma” (Königs \& Kaufmann, 1996, p. 19).

Analyzing the results of his research on the translation process, Lörscher reaches some similar conclusions. He points out that amateur translators (students learning a foreign language) usually adopt a form-oriented approach and monitor the emerging translation in terms of meaning only in those passages that have caused them translation problems. Therefore, they produce texts that are often not only not equivalent to the original but also contain grammatical and stylistic errors, even when these are texts in the subjects' native language. Contrastingly, professional translators usually adopt a meaning-oriented approach and continually monitor the emerging translation, thus avoiding distortions of the source text's meaning and errors in the target language (Lörscher, 2005, p. 605). In this regard, Tirkkonen-Condit believes that it is necessary to continue research of the monitoring mechanism experts apply to make sure that passages which were translated literally and are not equivalent to the original text or contain grammatical mistakes, are not left in the translation (Tirkkonen-Condit, 2005, p. 408).

To date, studies on translation strategies have been criticized mostly because of the imperfect tool they applied, i.e. think-aloud protocols. The great majority of studies were also conducted on samples too small (ten-odd and fewer subjects) 
to generalize the results or draw significant conclusions. Furthermore, previous empirical studies on translation strategies were not based on any psycholinguistic model of the translation process. Therefore, in the context of my $\mathrm{PhD}$ thesis I intend to conduct a study of translation strategies based on the cognitive-communicative model of the translation process of Krzysztof Hejwowski (2004). The study will be carried out on a sample of 60 subjects and will employ keystroke log data in combination with retrospection data.

\section{Translation strategies based on Hejwowski's theory. Results of a pilot study}

In his unpublished $\mathrm{PhD}$ dissertation Hejwowski (1992) lists the basic translation strategies as being superficial strategy, case frame selection strategy, scenario strategy and scheme strategy. These strategies correspond to the levels distinguished in the same author's translation model (2004) (for a detailed description of Hejwowski's model see Płońska, 2006; Płońska \& Bokus, 2010). In respect to the theoretical distinctions cited above, these strategies are textual and global production strategies.

According to Hejwowski (1992), the superficial strategy (called syntagmatic translation strategy in the author's book edited in 2004) is based on automatized knowledge of corresponding surface structures of two languages. This strategy allows a person to translate texts or passages that they do not fully understand. The case frame selection strategy is based on the knowledge, characteristic of all people, of a set of basic semantic roles and on the knowledge, characteristic of translators, of correspondences between different case frames of two languages. It allows a person to translate sentences to which they can assign an appropriate case frame, without the need to resort to frames and schemes of upper levels. The scenario strategy (strategy of scenes and scenarios according to the book edited in 2004) is based on the knowledge of typical sequences of events or actions. Its use usually requires some knowledge of the realities of both cultures. This strategy allows greater flexibility in translation, permitting significant changes at the surface level. Finally, the scheme strategy requires an explicit representation of the author, the audience and the translation situation, a good understanding of the essence of the problem, knowledge of the narrative framework applied by the author and of the corresponding narrative framework applied in the target language culture. Different elements of the cognitive base which determine the use of the scheme strategy are linked to corresponding sub-strategies which can predominate in a given act of translating, e.g. the translator can rely on their knowledge of the appropriate narrative framework rather than on the representation of the author or the audience.

In 2009 and 2010 a pilot study was conducted to ascertain whether professionals and amateurs differ in how often they follow an advanced translation 
strategy such as the strategy of scenes and scenarios (for the full description of the procedure, detailed results and discussion see Płońska \& Bokus, 2010). The impact of an initial text representation on the subsequent application of the strategy of scenes and scenarios was also studied. The study encompassed nine professional translators aged 30 to 63 and nine persons aged 23 to 37 not involved professionally in translation. The translators' work experience ranged from 5 to 38 years. The non-translators had DALF certificates confirming advanced-level French language skills.

It was expected that amateurs, compared to professionals, would apply a strategy requiring more in-depth text analysis, such as the strategy of scenes and scenarios, less often. Moreover, it was anticipated that forming an initial mental representation of text would soften the differences between the two groups.

The results of the pilot study are quite surprising. It turned out that not only do professionals not apply the strategy of scenes and scenarios more often than amateurs but there is a group of amateurs who apply such a strategy even more frequently than professionals (they were called "bold" amateurs). The results also showed that an initial mental representation of text has a substantial impact on the subsequent translation process in terms of the frequency of application of the strategy of scenes and scenarios. Subjects who formed a mental representation of the text before commencing translation more seldom abandoned the strategy of scenes and scenarios than subjects who did not form such a representation. Furthermore, those of the "bold" amateurs who formed an initial mental representation of the text applied the strategy of scenes and scenarios less often in the translation process as a whole than those who did not. They also deleted less text while translating, which suggests that they made fewer corrections. Interestingly, the influence of forming an initial mental representation of the text was the opposite in the groups of "cautious" amateurs and professionals. When they formed a representation of the text before commencing translation, both these groups made more frequent use of the strategy of scenes and scenarios (though the difference was not statistically significant). In addition, the "cautious" amateurs deleted more text in this situation, meaning they made more corrections (this effect was at the tendency level). Thus, according to expectation, having an initial representation of the text caused the differences between groups to decrease.

The pilot study results show amateurs as a heterogeneous group that includes not only persons who try to express the meaning of individual words but also those who conduct a more in-depth analysis of text and often produce translations on the basis of a representation of entire scenes or scenarios. Additionally, the results suggest the importance of forming a mental representation of a text before commencing translation for the subsequent course of the process.

A more complete image of the translation process could be gained from research on how different groups of people apply a strategy opposite to the one 
described here, namely the superficial strategy. In my ultimate study I also plan to take a closer look at the subjects' errors by analyzing the entire process of making corrections.

\section{References}

Bell, R.T. (1998). Psycholinguistic/cognitive approaches. In M. Baker (Ed.), Routledge Encyclopedia of Translation Studies (pp. 185-190). London: Routledge.

Chesterman, A. (1997). Memes of Translation: The Spread of Ideas in Translation Theory. Amsterdam: John Benjamins.

Hejwowski, K. (1992). Psycholingwistyczny model procesu ttumaczenia [The Psycholinguistic Model of the Translation Process]. Unpublished PhD dissertation, University of Warsaw.

Hejwowski, K. (2004). Kognitywno-komunikacyjna teoria przekładu [The CognitiveCommunicative Theory of Translation]. Warszawa: Wydawnictwo Naukowe PWN.

Jääskeläinen, R. (1996). Hard work will bear beautiful fruit. A comparison of two think-aloud protocol studies. Meta, 41 (1), 60-74.

Kearns, J. (2009). Strategies. In M. Baker and G. Saldanha (Eds.), Routledge Encyclopedia of Translation Studies (pp. 282-285). London: Routledge.

Königs, F.G. \& Kauffmann, R. (1996). Processus mentaux étudiés chez des sujets allemands apprenant le français lorsqu' ils sont en train de traduire. Meta, 41(1), 7-25.

Lörscher, W. (1991). Translation Performance, Translation Process and Translation Strategies: A Psycholinguistics Investigation. Tübingen: Gunter Narr.

Lörscher, W. (2005). The translation process: Methods and problems of its investigation. Meta, 50 (2), 597-608.

Newmark, P. (1988). A Textbook of Translation. New York: Prentice Hall.

Płońska, D. (2006). Process of translation from the psycholinguistic perspective. A review of: Krzysztof Hejwowski, Kognitywno-komunikacyjna teoria przekładu (The cognitive-communicative theory of translation). Psychology of Language and Communication, 10 (1), 101-106.

Płońska, D. \& Bokus, B. (2010). Advanced translation strategies exclusively for professionals? Results of a process-oriented translation study. In B. Bokus (Ed.), Studies in the Psychology of Language and Communication (pp. 227-248). Warsaw: Matrix.

Tirkkonen-Condit, S. (2005). The monitor model revisited: Evidence from process research. Meta, 50 (2), 405-414.

Vinay, J.-P. \& Darbelnet, J. (1958/2000). A methodology for translation. In L. Venuti (Ed.), The Translation Studies Reader (pp. 84-95). London: Routledge. 